\title{
La web corporativa en las empresas biotecnoló- gicas de los Parques Tecnológicos de Andalucía (2013). Una propuesta de análisis de prácticas de comunicación a través de plataformas online
}

\author{
Juan Salvador VICTORIA MAS \\ Universidad de Málaga \\ jsvictoria@uma.es \\ Ma Luisa GARCíA HeRnÁNDEZ \\ Universidad de Málaga \\ mluisagarcia@uma.es
}

\begin{abstract}
Resumen
Como se ha demostrado en numerosos estudios, las pymes españolas con web propia suelen plantear ese espacio digital como un simple escaparate donde mostrar productos y servicios, un lugar escasamente interactivo dirigido a clientes y proveedores. Esta investigación parte de la base de que tal planteamiento persiste en el caso de las empresas biotecnológicas. En las webs de este sector encontramos falta de interactividad hacia sus públicos propios, y también hacia el resto de la sociedad: para éstos sería necesaria una comunicación de tipo divulgativo. La muestra elegida la conforman las empresas asentadas en parques tecnológicos andaluces.
\end{abstract}

Palabras clave: Comunicación; empresas biotecnológicas; parques tecnológicos; ciudadanía

The corporate web in the biotech companies of the Andalusian Technology Parks (2013). A proposed analysis of Communication practices through online platforms

\begin{abstract}
As demonstrated frequently in numerous studies, Spanish SMEs own web often offers the digital space as a mere 'window', a barely interactive exhibition which presents a conventional exposition of products and services. This research assumes that such an approach persists in the case of biotechnology companies websites. For the sites in this sector, we find lack of interactivity to their own public, and also to the public that make the rest of society: for these, even with specific interests in biotech content, would require a informative type communication. The sample chosen the make up companies based on technology parks in Andalusia.
\end{abstract}

Key words: Communication, biotech firms, technology parks, citizens

Referencia normalizada:

Victoria Mas, J. S. y García Hernández, M. L. (2013). La web corporativa en las empresas biotecnológicas de los Parques Tecnológicos de Andalucía (2013). Una propuesta de análisis de prácticas de comunicación a través de plataformas online. Historia y Comunicación Social Vol. 18 № Especial Octubre. Págs. 61-.73 
Sumario: 1. Introducción. 2. Metodología. 2.1 La página de inicio. 2.2. Las páginas del sitio. 3. Resultados. 3.1. La página de inicio. 3.2. Las páginas del sitio. 4. Conclusiones y comentario de resultados. 5. Referencias bibliográficas.

\section{Introducción}

Cualquier empresa, con independencia de su tamaño, tiene necesidad de entablar una comunicación fluida con diferentes públicos y no centrarse en exclusiva en clientes y proveedores. El hecho de que sus productos o servicios no estén a disposición de un público masivo o que su cliente final sean empresas o instituciones no implica que deban desatender a sus vecinos, porque con ellos comparten problemas, expectativas, necesidades, recursos, etc. Las empresas son parte activa de la sociedad, un miembro más, que no puede vivir aislado de su entorno (Grunig, 2003; Villafañe, 1999; San Nicolás Romera, 2005; Costa, 2009; García Perdiguero, 2005; Valbuena de la Fuente, 1997).

La creación de parques tecnológicos viene a facilitar las sinergias entre empresas, casi todas de base tecnológica (EBT), pero no han solucionado una falta de relación con el exterior, que suele agravarse en el caso de las pequeñas, debido a la escasez de medios materiales y humanos de los que disponen. Así, esos recintos pueden correr el riesgo de convertirse para ellas en un gueto, espacios cerrados y aislados de la vida que discurre a su alrededor.

En el caso específico de las pymes biotecnológicas, a esas dificultades se suma que sus actividades son complejas, y para facilitar su comprensión por parte de personas con escasa formación científica precisan adquirir un nuevo lenguaje, más cercano y asequible, así como abordar temas fuera de lo inmediato, es decir, implicarse en tareas de divulgación de las que han permanecido ajenas y de las que pueden obtener ventajas en términos de imagen para las firmas implicadas. Tal oportunidad deriva del interés que despierta entre los ciudadanos la ciencia en general (Fecyt, 2012; Fundación BBVA, 2012) y la biotecnología en particular (European Commission, 2010), así como de las expectativas que tienen en ella depositada, para mejorar su calidad de vida, y que no se cubre exclusivamente con el incremento de la cobertura que los medios dan a informaciones relacionadas con la biotecnología, o sobre empresas e instituciones ocupadas en esas tareas (Observatorio Zeltia, 2013; Escribano \& Quintanilla, 2005).

Con ese enfoque, las empresas atenderían a resolver incertidumbres que atañen directamente a la biotecnología y que, en función de la actividad concreta de cada una, se centrarían en temas como la investigación con células madre, ingeniería genética, degeneración neuronal, producciones agrícolas más resistentes a sequias o plagas, por citar algunos. Se trata de complementar a las vías tradicionales, enciclopédicas, que se muestran insuficientes para resolver inquietudes sociales; de diseminar la información científica bajo todas las formas y por cualquier medio; de "abrir las puertas de los laboratorios, como antaño se hizo con los conventos" (Reguera 2004: 37). 
Otros públicos a los que atender son los posibles inversores. Cabe recordar que la inversión de capital riesgo en España en 2012 ascendió a 2.472 millones de euros (Informe ASCRI, 2013) cifra en la que se integran los 230,6 millones de euros correspondiente a inversión en venture capital. Un capítulo en el que el sector de la biotecnología aparece en segunda posición, tras el de la informática, en captación de este tipo de fondos (webcapitalriesgo, 2012).

En este estudio nos centramos en los parques tecnológicos andaluces porque son de reciente creación; las biotecnológicas que acogen son casi todas pymes, salvo algunas filiales o laboratorios dependientes de multinacionales, que exceden el ámbito de este estudio, y son mayoritariamente spin off universitarias o del CSIC. Además, según el informe ASEBIO 2012, Andalucía se ha situado de forma consecutiva durante los últimos cuatro años como la región que más empresas biotecnológicas ha creado, lo que la situaba como la tercera comunidad autónoma española por volumen de biotec, al acaparar el $13,5 \%$ de la totalidad nacional, y la segunda en número de empresas usuarias de biotecnología con el 10,89\%.

Nuestro punto de partida es que con ese panorama la web corporativa de cada una de esas empresas por su interactividad, bajo coste, espacio disponible ilimitado, etc. es una herramienta ideal para facilitar la comunicación con su entorno, inversores y con la sociedad en general. Si bien es un instrumento cuyo valor en la comunicación corporativa deber complementarse con otro tipo de actuaciones que faciliten hallar puntos de encuentro con colectivos ciudadanos, entidades educativas, organismos públicos y privados, etc.

Con esa base entendemos conveniente analizar qué uso dan a su sitio web, cómo se comunican estas compañías a través de ella, dónde focalizan sus discursos y a quienes los dirigen, entre otras cuestiones. Es la forma de comprobar si un sector que pretende ser importante en la economía de una región, y de un país, se ocupa también de serlo en la mente de la población.

En definitiva, en este estudio nos centramos en un foco de actividad muy concreto, el de las pymes biotecnológicas, reducimos el marco espacial a aquellas ubicadas en los cuatro principales parques tecnológicos andaluces, Ciencias de la Salud de Granada, Rabanales 21 de Córdoba, PTA de Málaga y Cartuja de Sevilla; y en cuanto a las herramientas para facilitar esa relación atendemos a la más accesible de ellas, la web corporativa, al entender como explica Becerra (2010: 208) que tal presencia implica "la toma de conciencia de la empresa sobre sí misma más allá del producto y servicio que comercializa".

La selección se justifica, igualmente, en que, aunque han proliferado en los últimos años los análisis de sitios web corporativos, casi siempre se han centrado en grandes empresas (Callison, 2003; González Herrero y Ruiz Valbuena, 2006; Sanz y Pallás, 2010) y son menos los trabajos que se han detenido en pymes o en sectores concretos (García, Carrillo y Castillo, 2012; Huertas y Xifra, 2009). 


\section{Metodología}

Para esta investigación hemos procedido a identificar las empresas biotecnológicas asentadas en parques tecnológicos andaluces. En total nuestro objeto de estudio lo constituyen 30 empresas, todas ellas pymes, repartidas entre los parques Ciencias de la Salud de Granada, Rabanales 21 de Córdoba, Parque Tecnológico de Andalucía de Málaga y Cartuja de Sevilla. El marco, por tanto, lo constituye su lugar de asentamiento y su actividad, la biotecnología, entendiendo por tal la definición que aparece en el artículo 2 de la Convención sobre Diversidad Biológica de las Naciones Unidas (UNEP, 1992), como "cualquier aplicación tecnológica que usa sistemas biológicos, organismos vivos o sus derivados, para crear o modificar productos y procesos para usos específicos".

La combinación en el trabajo de métodos cualitativos de investigación, cuantitativos y estadísticos ha sido una elección meditada, para comprobar si los resultados obtenidos con cada uno de ellos entraban en contradicción con el resto o no.

\subsection{La página de inicio}

Entendemos con Austin (1982) que el lenguaje que se utiliza en los textos de esas webs, como en cualquier otro texto, es un vehículo para describir o expresar ideas, pero también esa selección de palabras no es aleatoria y participa en la construcción de la realidad social, es un modo de acción. De tal forma que el discurso no sólo tiene sentido, sino también intencionalidad. Para encontrarla seguimos algunas de las pautas marcadas por Barthes (1977) y construimos unas plantillas, en las cuales recogemos distintas informaciones que aportan cada uno de los discursos expuestos en la página de inicio de los sitios. En ellos hemos buscado la sintaxis predominante, núcleos temáticos y unidades semánticas principales, que articulan el significado del texto. Igualmente, hemos segregado los códigos utilizados en cada uno de esos textos, códigos de acción o de comportamiento, simbólicos, interpretaciones (hermenéutica), características y descripciones.

También atendemos a los públicos a los que van dirigidos los discursos objeto de estudio, porque entendemos que, normalmente, cuando el autor compone el texto lo hace de acuerdo a unas competencias que él tiene y que espera que comparta el lector, de tal forma que su interpretación se corresponda con las expectativas del autor. Pero sobre este asunto apunta Eco (1981) que los textos también pueden contribuir a crear esas competencias, con lo que entraríamos, en cierto sentido, en el campo de la divulgación.

Muy relacionado con ese aspecto está la propuesta que hacemos para abordar nuestro análisis de contenido. Queremos comprobar, a través de dos bloques de palabras, uno ligado al ámbito empresarial e investigador y otro más cercano a un plano social, relacional, cómo se presentan las compañías y a qué tipo de públicos se dirige. Así, hemos compuesto un corpus de ocho sustantivos, cuatro de ellos referidos a la actividad de estas empresas, campos semánticos de negocio, usos, innovación y 
tecnicismos; el resto se engloba en sus vinculaciones con el contexto físico y social, no sólo el más próximo, con sociedad, entorno, beneficios y persona. De esta forma pretendemos que todos los contenidos tengan idénticas posibilidades de aparecer en los textos. Además, hemos comprobado la presencia de la preposición para y de oraciones subordinadas finales.

También abordamos el análisis de las imágenes que ilustran los textos lingüísticos de inicio de los sitios, unos recursos gráficos que, intencionalmente, se han seleccionado y que dan cuenta de cómo se quiere mostrar cada una de las empresas.

\subsection{Las páginas del sitio}

Otro bloque de análisis lo constituyen las características físicas, técnicas y de organización de las diferentes páginas que componen los sitios. Con esa perspectiva analizamos las variables usabilidad, utilidad e interactividad. Aunque las abordemos por separado tomamos en consideración la relación entre las dos primeras variables de la que alertan Hassan y Ortega (2009:10), cuando apuntan que "la usabilidad también representa el grado en que esta utilidad es percibida por el usuario. No es posible, por tanto, hablar de usabilidad y utilidad como factores desconectados o independientes".

En la variable usabilidad hemos utilizado indicadores tales como el tiempo de carga del sitio, permanencia del menú de acceso en todas las secciones, existencia de un mapa web, buscador interno y legibilidad, entre otros. Mientras que para discriminar la utilidad que esos sitios presentan para distintos tipos de usuarios contamos con criterios como la opción de acceso en varios idiomas, la posibilidad de consultar dosieres o informes, información empresarial y personal sobre los gestores y ubicación de la empresa.

En cuanto a la interactividad se ha establecido sobre diversos criterios, entre los que figuran la presencia en redes sociales (entradas y seguidores); la existencia de formularios de solicitud de información, quejas o sugerencias; posibilidad de realizar pedidos en línea; enlaces externos; actualizaciones y datos de contacto.

Por último, para comprobar si las empresas analizadas atienden a través de sus webs a los medios como audiencia, dado que representan una vía intermedia para conectarla con la sociedad, hemos seguido de forma esquemática el patrón que emplearon González Herrero y Ruiz de Valbuena (2006) en su estudio sobre las relaciones de compañías internacionales con los medios a través de sus webs. Entre los criterios que utilizaron aparecían la denominación con la que se identifica la sala de prensa virtual; el número de clics necesarios para llegar a ella; la disposición de elementos de seguridad en el acceso; criterios en la organización de contenidos; la incorporación de dosieres e informes temáticos; la disponibilidad de imágenes para descargar; la suscripción para novedades, RSS, e identificación de las personas para atención a medios. 


\section{Resultados}

Los distintos tipos de análisis que hemos utilizado, lejos de complicar la obtención de resultados, nos han mostrado la uniformidad en los planteamientos, formatos, temáticas y enfoques en los treinta sitios web estudiados.

\subsection{Página de inicio}

En referencia a la sintaxis utilizada en cada uno de esos textos podría parecer en un principio bastante sencilla, ya que predominan las oraciones compuestas coordinadas copulativas y algunas yuxtapuestas, junto a oraciones simples copulativas y frases nominales. Pero esa simplicidad sintáctica aparente se complica por la tendencia a acumular elementos y alargar en exceso las oraciones, con preeminencia de las comas frente a otros signos de puntuación.

A esa traba se suma que las unidades significativas principales, las que acumulan la carga semántica, se concentran en elementos, sustantivos sobre todo, sacados directamente de los campos de la ciencia y la tecnología. Por el contrario, los verbos, habitualmente en modo indicativo, suelen ser de baja carga léxica. Unas formas verbales que aparecen sólo en tercera persona del singular en más de la mitad de los textos, o en combinación con la primera del plural para alcanzar las $3 / 4$ partes de los contenidos objeto de análisis.

Si subimos un nivel entramos en el asunto o tema del texto, a cuyo servicio estarían los elementos que lo componen (Van Dijk, 1990). En este punto destacamos que la mayoría de las empresas optan por una estructura expositiva en la que combinan las referencias al quién soy con el qué hago, las dos terceras partes del total, y sólo el $10 \%$ añade alguna referencia, tangencial, a las consecuencias de su actividad. El resto se limita a exponer el qué hago.

En cuanto a los códigos utilizados, el $85 \%$ se reduce a describir acciones y características de esas acciones (labores que ejecuta la empresa) o de sus productos y servicios, en exclusiva.

Una simple mirada al cuadro producto de la aplicación del análisis de contenido nos ofrece una primera visión, que separa los resultados en dos bloques perfectamente diferenciados. En la segunda mitad es muy mayoritaria la presencia de las palabras que hacen referencia a la actividad de las empresas analizadas. La ausencia es, por el contrario, la característica que predomina en la primera mitad, la relacional. 


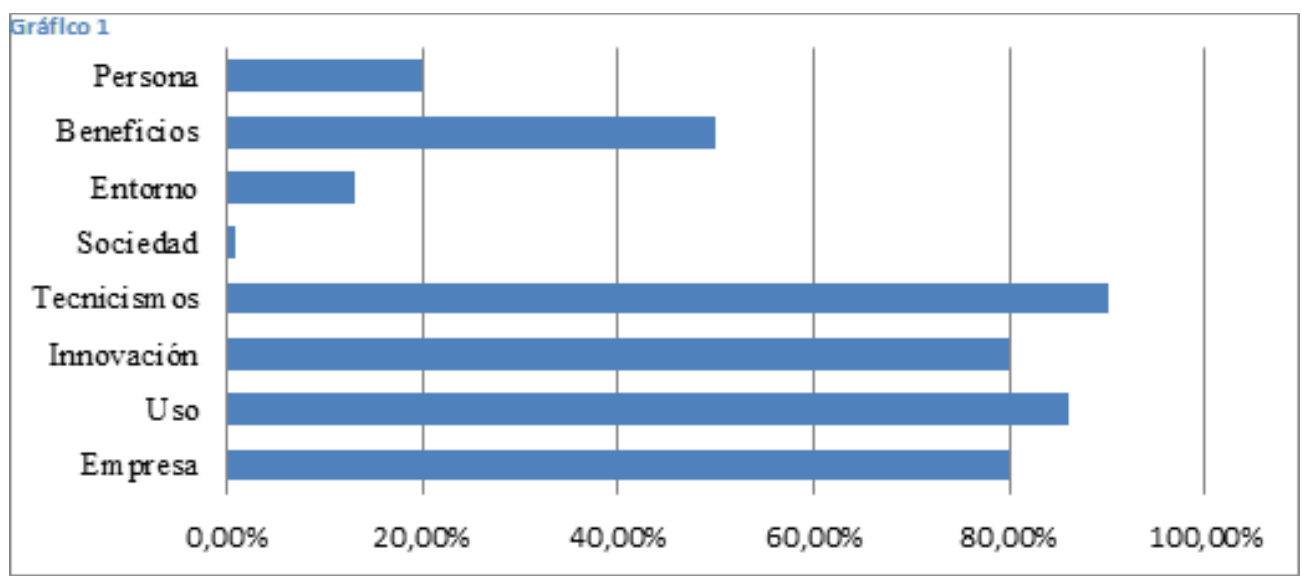

Los resultados son bastante explícitos, sin embargo, conviene hacer tres matizaciones. La primera hace referencia a la palabra beneficios que, como el resto, está abordada como campo semántico. Pues bien, en esas páginas se alude al tratamiento (de enfermedades); mejora (de la salud); aprovechamiento (de residuos); pero sin profundizar en ninguno de ellos, sin alusión alguna a otros provechos que su actividad genera, tales como la creación de riqueza y empleo, y sin referencias a los individuos que se beneficiarán de sus productos, servicios o procesos. Muy relacionada con esta está la segunda aclaración, ya que los términos relativos a persona, no sólo escasean, sino que el $20 \%$ que los contempla lo hace en contextos tales como "investigación y tecnología aplicada al bienestar del hombre" o "mejora de la calidad de vida", lo que implica un cierto distanciamiento que no parece casual. Además, en varios textos se hace referencia a enfermedades, pero no a las personas que los padecen y, en los casos en que se alude a ellas, aparecen con la palabra paciente. La tercera trata sobre la aparición de términos técnicos, que se recogen en el 90\% de los casos; si bien es cierto que esos tecnicismos tienen una alta variabilidad. Desde aquellas páginas de inicio, en especial una, en la que este tipo de voces aparecen encadenadas para convertir el texto en jerga, hasta aquellas en las que su presencia es casi testimonial y, aunque se trate de palabras propias de su técnica, están asimiladas en registros menos formales.

Otro bloque lo constituye la preposición para y nexos que introducen oraciones finales, que están presentes en el $70 \%$ de las páginas analizadas. Sin embargo, lo que recogen a continuación no es el para qué de su actividad, que es lo que queríamos comprobar, sino construcciones como "satisfacción de sus clientes" o "resolver problemas de" sin detenerse en las consecuencias finales de esa actividad, esto es, las repercusiones específicas.

En cuanto a las imágenes que ilustran las páginas de inicio, los laboratorios o elementos propios de ese tipo de instalaciones, pipetas, matraces, tubos de ensayo o microscopios, entre otros, tienen la primacía, están presentes en el 44\%. Si añadimos otros elementos como bacterias, células, estructuras moleculares, de ADN y neurona- 
les, en distinto grado de esquematización, la presencia supera las tres cuartas partes. Por el contrario, figuras humanas que podríamos entender ajenas al ámbito de la investigación y, por tanto, receptoras de los beneficios que generan esas empresas, no alcanzan una cuarta parte del total.

\subsection{Las páginas del sitio}

Salvo en los dos casos de sitios empresariales en los que hay una página de introducción, el resto presenta un tiempo de carga ágil, de hecho ninguna supera los 3 segundos de espera. Igualmente, la uniformidad preside la permanencia del menú de acceso en cualquiera de las secciones a la que accedamos. Sólo dos de ellas suponen la excepción.

Otros dos indicadores con los que hemos operado han sido los referidos a la carga visual de las páginas y la legibilidad de los textos, criba que la mayoría ha superado de forma holgada.

Por otra parte, la mitad de las empresas estudiadas cuentan con la presencia de mapa web, una herramienta que facilita y orienta la navegación del visitante. Algo menos, el $40 \%$, proporciona la ayuda de un buscador interno. En cuanto a la posibilidad de acceder en varios idiomas, el $61 \%$ propone versiones en, al menos, dos idiomas, inglés y español. El 16\% se fija sólo en inglés y el 23\% exclusivamente en español. Y sólo el 35\% de los sitios analizados inserta algún dosier desde donde ampliar información que satisfaga las necesidades de grupos concretos de visitantes.

Muy relacionado con este apartado, y la restricción en la oferta de información de la que hacen gala estos sitios, está el capítulo económico-empresarial. En las web analizadas no aparecen datos de carácter económico, salvo los correspondientes a una cotizada que está obligada a ello por sendas leyes. Y si la información económica es trascendente puesto que genera confianza entre posibles inversores, además de usuarios o clientes, también lo es la correspondiente a los gestores que están detrás de cada empresa. Sus nombres, formación y experiencia sólo aparecen en el 10\% de los sitios y otro $7 \%$ se limita a dar sus nombres y forma de contacto.

Para la variable interactividad nos hemos apoyado en varios indicadores. En el relativo a existencia de enlaces a redes sociales catorce de los sitios acogen los logos de, al menos, una de ellas, pero al clicar encontramos que en dos estamos ante enlaces muertos, lo que reduce el porcentaje al $40 \%$. De entre ellos el más habitual es Twitter, presente en el 33\% de los sitios; seguido Facebook, el 30\%; Linkedin el 26\% y Youtube el 13\%. Además, las actualizaciones escasean y sólo la mitad de ellas se pueden considerar activas en alguna de las redes en las que tienen presencia.

La insuficiente renovación de contenidos no se limita a ese ámbito. Algunos de los sitios podrían no haberse alterado desde que se crearon y en otros las novedades de sus contenidos, centrados en el ámbito de noticias se remontan, al menos, seis meses atrás. Ambas categorías suman el $62 \%$. 


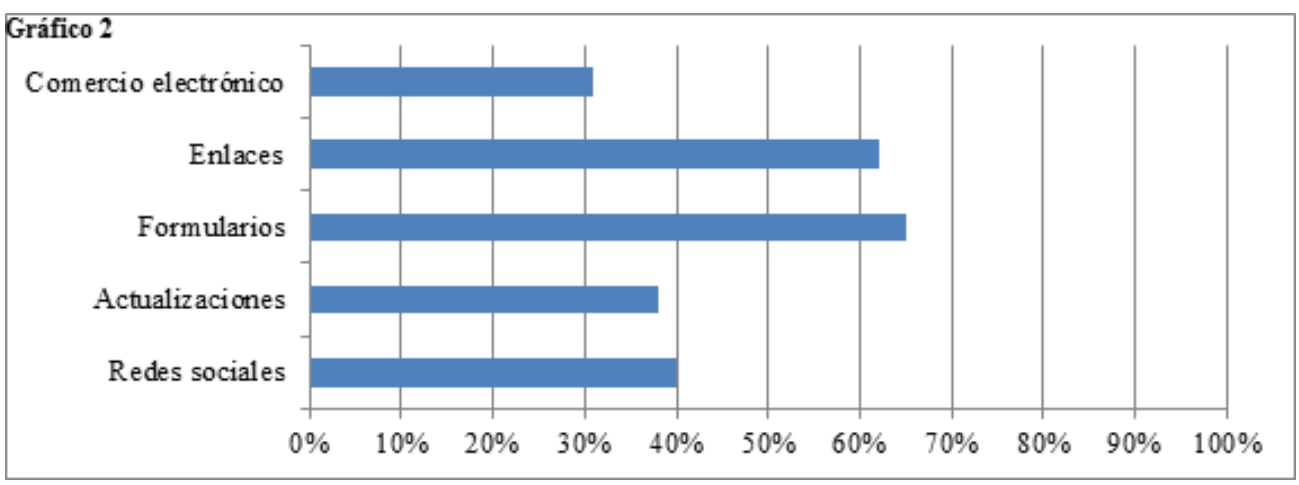

Otros mecanismos de comunicación con la ciudadanía son los formularios de contacto, quejas o sugerencias en la web, un mecanismo instalado en el $65 \%$ de los sitios. Porcentaje similar, el $62 \%$ corresponde a los sitios que incluyen enlaces externos, en número muy reducido; normalmente a empresas, asociaciones u organismos con los que mantienen algún tipo de relación. Una cerrazón común al resto de empresas españolas y que Celaya y Herrera (2007:181), explican en el temor a que los lectores se marchen a otro sitio, olvidando que "obtienen un posicionamiento más alto en los buscadores dado que el algoritmo premia aquellas webs que enlazan con otras" y que esta apertura supone un servicio a sus lectores, al ofrecerles conexión a contenidos que pueden complementar a los de la propia empresa.

Mencionar, igualmente, que el comercio electrónico está presente en el 31\% de los sitios analizados y que las vías de contacto propuestas por las empresas en sus sitios son, al menos, tres; con predominio del formato que incluye dirección postal, teléfono y dirección electrónica.

El espacio que podríamos considerar como sala de prensa virtual no existe como tal en ninguno de los sitios analizados; lo más parecido es un cajón de sastre bajo el epígrafe Noticias, dispuesto en el 80\% de los casos. En él se recogen notas de prensa, varias sin datar; apariciones en medios, algunas con link muertos; lanzamientos de productos; acuerdos comerciales; etc. Solo una incluye en esta sección dos dosieres, en el resto ya hemos comprobado que aparecen, cuando los hubiere, en otras áreas; ninguna dispone de imágenes para descargar, ni recursos multimedia, cuyo acceso se dispone a través de Youtube en los sitios en que los ofrecen. Carecen, igualmente, de sindicación de contenidos, aunque el 13\% ofrece la posibilidad de suscripción a una newsletter.

\section{Conclusiones y comentario de resultados}

Hemos comprobado a lo largo de este trabajo que persisten en este grupo de empresas los problemas que García, Carrillo y Castillo (2012) han detectado en los sitios de otras pymes y Victoria (2005) en todo tipo de sectores corporativos, esto es, afán 
expositivo en lugar de primar el diálogo con sus visitantes. La escasa presencia en las redes sociales y de actualizaciones en los sitios y en las redes apoyan tal apreciación.

Con Olvera-Lobo y López-Pérez (2013) coincidimos en que, tal y como señalan en su estudio sobre el CSIC, a través de las web corporativas los centros públicos de investigación pueden realizar una función divulgadora que contribuya a mejorar el conocimiento científico de los españoles. Nosotros añadimos que esa deuda social también corresponde pagarla a las empresas que tienen en la investigación su razón de ser. Tal propuesta tiene su base en que Internet se ha convertido para los españoles en la primera fuente de información científica (Fecyt 2012) y las empresas se están quedando al margen de una vía que, además, puede contribuir a que sean más conocidas y valoradas por la sociedad. Los resultados de nuestro análisis de contenido dan cuenta de que las empresas analizadas no se han dado por aludidas en ese ámbito.

La relación con su entorno más próximo es otro déficit que las biotecnológicas objeto de análisis deben superar, descartar el acercamiento a ese público a través de la web, con la única excusa de que entre él no hay clientes, se nos antoja una actitud miope.

Otros auditorios desatendidos son los de analistas y posibles inversores. No disponen los sitios analizados de información económica, salvo una cotizada, y sobre sus gestores dan cuenta menos de una quinta parte de ellos, a pesar de que una gestión transparente puede atraer capital procedente de cualquier parte del mundo y de que las dificultades de acceso a la financiación y al crédito lastran el crecimiento de las pymes, en especial, como es nuestro caso, de aquellas que precisan un tiempo de maduración para dar frutos.

Y en la misma línea está la consideración a los medios, a los que no se les ofrece un espacio específico, ni los recursos precisos para entablar una relación fructífera.

El enfoque de los discursos hacia el quién soy y qué hago, obviando el para qué y para quiénes lo hago, así como las repercusiones socioeconómicas de su actividad, sólo precisa para corregirse una modificación de perspectiva, una mejor comprensión de las necesidades y expectativas del otro. De esa falta de complicidad con los lectores también dan cuenta el léxico seleccionado, la preeminencia de verbos con escasa carga semántica, en indicativo y en $3^{\mathrm{a}}$ persona, todos elementos propios de los textos descriptivos y expositivos.

Sin embargo, todas ellas son cuestiones remediables a poco que se le ponga un poco de voluntad; sobre todo si tenemos en cuenta que se trata de modificar puntos de vista y que, como ventaja técnica, tenemos que se trata, en su mayor parte, de sitios de fácil manejo, atractivos visualmente y sin grandes abigarramientos.

Parece conveniente aludir también a que no hemos detectado en las webs analizadas ningún tipo de interconexión entre las empresas biotecnológicas analizadas, aún cuando comparten espacio físico en recintos especializados y sector productivo, un ámbito que sería aconsejable explorar, dado que los recursos disponibles en las pymes 
analizadas son limitados y que las empresas biotecnológicas están acostumbradas a cooperar en otros asuntos (Holl y Rama, 2012), no así en temas de comunicación.

Este trabajo nos ha permitido acercarnos a la disección de los sitios web de varias empresas biotecnológicas, con distintas herramientas, para obtener de ellas una visión de conjunto, pero esa amplitud de foco nos ha impedido profundizar en aspectos que merecían un examen más minucioso y que quedan para posteriores investigaciones. Además, se abren ante nosotros nuevas sendas que deberemos transitar referidas a la comunicación de este sector, pero no sólo a través de Internet.

\section{5.- Referencias bibliográficas:}

AUSTIN, J. L. (1982). Cómo hacer cosas con palabras: palabras y acciones. Barcelona: Paidós.

BARTHES, R. (1977). "Introducción al análisis estructural de los relatos". En NICCOLINI, S. (comp.) El análisis estructural. Buenos Aires: Centro Editor de América Latina.

BECERRA, E. (2010). "El escaparate online de la empresa. Un nuevo espacio para la comunicación corporativa". Icono $14 \mathrm{n}^{\mathrm{o}}$ 15. p. 207-219 Disponible en: http:// www.icono14.net/ojs/index.php/icono14/article/view/290/167 [08-06-2012]

CALLISON, C. (2003). "Media relations and the Internet: How Fortune 500 company Web sites assist journalists in news gathering". Public Relations Review, $\mathrm{n}^{\mathrm{0}} 29$. $\mathrm{p}$. 29-41.

CELAYA, J.; HERRERA, P. (2007). Comunicación empresarial 2.0. Barcelona: Grupo BPMO Ediciones.

COSTA, J. (2009). El DirCom hoy. Dirección y gestión de la comunicación en la nueva economía. Barcelona: Costa Punto Com.

ECO, U. (1981). Lector in fabula. La cooperación interpretativa en el texto narrativo. Barcelona: Lumen.

EUROPEAN COMMISSION (2010). Europeans and Biotechnology in 2010. Winds of change? Luxembourg: Publications Office of the EU. Disponible en: http:// ec.europa.eu/public_opinion/archives/ebs/ebs_341_winds_en.pdf [20-05-2012].

FECYT. (2012). Sexta Encuesta de Percepción Social de la Ciencia. Disponible en: http://www.fecyt.es/fecyt/docs/tmp/363174605.pdf [30-04-2013].

Fundación BBVA (2012) Estudio Internacional de Cultura Científica. Comprensión de la ciencia. Disponible en: http://www.fbbva.es/TLFU/dat/comprension.pdf [04-09-2012].

GARCÍA, M.; CARRILlO, M. V.; CASTILlO, A. (2012). "La usabilidad en los portales web de las pymes. Herramientas y usos para la comunicación empresarial". Estudios sobre el Mensaje Periodístico, $\mathrm{N}^{\mathrm{o}}$ 18. p. 365-375. Disponible en: http://revistas.ucm.es/index.php/ESMP/article/view/40990/39241. [13-01-2013].

GARCÍA PERDIGUERO, T. (2005). "Una revisión crítica de las relaciones empresa y sociedad”. En VILLAFAÑE, J. (ed.) La comunicación empresarial y la gestión 
de los intangibles en España y Latinoamérica. Madrid: Ediciones Pirámide. p. 157-186.

GONZÁLEZ HERRERO, A.; RUIZ DE VALBUENA, M. (2006). "Trends in online media relations: Web-based corporate press rooms in leading international companies". Public Relations Review, no 32. p. 267-275.

GRUNIG, J. E. \& HUNT, T. (2003). Dirección de Relaciones Públicas. Barcelona: Gestión 2000.

HASSAN, Y. \& ORTEGA, S. (2009). Informe APEI sobre usabilidad. Gijón: APEI.

HOLL, A.; RAMA, R. (2012). "Technology sourcing: Are biotechnology firms different? An exploratory study of the Spanish case". Science and Public Policy, n ${ }^{\circ} 39$. p. 304-317. [29-04-2013].

HUERTAS, A.; XIFRA, J. (2009). “Marcas o genéricos? La comunicación en línea de las marcas farmacéuticas". Zer, nº 27 . p. 251-270. Disponible en: http://www. ehu.es/zer/hemeroteca/pdfs/zer27-12-huertas.pdf. [08-04-2013].

OLVERA-LOBO, M. D.; LÓPEZ-PÉREZ, L. (2013). "La divulgación de la ciencia española en la Web 2.0: el caso del CSIC en Andalucía y Cataluña". Revista Mediterránea de Comunicación, $\mathrm{n}^{\circ}$ 4. p.169-171. Disponible en: http://mediterranea-comunicacion.org/index.php?journal=Mediterranea\&page $=$ article\&op $=$ view\&path $\% 5 \mathrm{~B} \% 5 \mathrm{D}=48 \&$ path $\% 5 \mathrm{~B} \% 5 \mathrm{D}=139$. [16-06-2013].

REGUERA, I. (2004). "Divulgación de la ciencia, canon científico, imagen del mundo". En ALONSO, A.; GALÁN, C. (ed.) La tecnología y su divulgación: Un enfoque transdisciplinar. Barcelona: Antropos. p. 13-52.

SAN NICOLÁS ROMERA, C. (2005). Comunicación Institucional y Corporativa. Murcia: Universidad de Murcia.

SANZ, C. J.; PALLÁS, A. B. (2010). "Análisis comparativo de las páginas web entre empresas del Ibex 35 y del sector de consumo". Partida Doble, no 219. p. 66-83 Disponible en: http://revistacontable.dev.nuatt.es/noticias_base/an\%C3\%A1lisiscomparativo-de-las-web-de-empresas-del-ibex-35-y-el-sector-consumo. [08-062012].

UNEP. (1992). Convention on biological diversity. United Nations Environment Programme. Mayo, 11-22, Nairobi (Kenya).

VALBUENA DE LA FUENTE, F. (1997). Teoría general de la información. Madrid: Némesis.

VAN DIJK, T. A. (1990). La noticia como discurso. Comprensión, estructura y producción de la información. Barcelona: Paidós.

VICTORIA, J. S. (2005). Reestructuras del Sistema Publicitario. Barcelona: Ariel Comunicación.

VILLAFAÑE, J. (1999). La gestión profesional de la Imagen Corporativa. Madrid: Ediciones Pirámide. 


\section{Los autores}

Juan Salvador Victoria Mas es Profesor titular de Comunicación Audiovisual y Publicidad en la Universidad de Málaga. Profesor visitante en varias universidades de Estados Unidos, Holanda y Polonia. Autor de seis libros y medio centenar de artículos sobre comunicación audiovisual, comercial e interactiva.

Ma Luisa García Hernández. Doctoranda (UMA) es Licenciada en Periodismo y en Filología. Máster en Periodismo (Grupo Vocento y UPV). Máster Oficial en Gestión Estratégica e Innovación en Comunicación (UMA). Experiencia profesional desarrollada en medios económicos y gabinetes de prensa. 